\title{
Tempering Effects of Multitrack Laser Surface Heat Treatment of AISI 1045 Steel
}

\author{
Chi-Liang Kung, ${ }^{1}$ Hao-En Shih, ${ }^{2}$ Chao-Ming Hsu, ${ }^{1 *}$ and Cheng-Yi Chen ${ }^{3,4^{* *}}$ \\ ${ }^{1}$ Department of Mechanical Engineering, National Kaohsiung University of Science and Technology, \\ Kaohsiung 80778, Taiwan \\ ${ }^{2}$ Department of Mechanical and Electro-Mechanical Engineering, National Sun Yat-sen University, \\ Kaohsiung 804, Taiwan \\ ${ }^{3}$ Department of Electrical Engineering, Cheng Shiu University, Kaohsiung 83347, Taiwan \\ ${ }^{4}$ Super Micro Mass Research and Technology Center, Cheng Shiu University, Kaohsiung 83347, Taiwan
}

(Received November 30, 2018; accepted January 11, 2019)

Keywords: laser surface heat treatment, hardening width, hardening depth, tempering effect

A thermo-elastic-plastic finite element model was employed to simulate and analyze the effects of high-power parameters on the laser heat treatment of AISI 1045 steel. Tempering effects of multitrack laser heat treatment using various process parameters-laser power, laser feed rate, laser overlap rate, and laser spot size - were analyzed to estimate the distribution of a hardening layer on the steel surface. Numerical simulation results indicated that the proposed finite element model is effective in analyzing the laser heat treatment of the steel surface and calculating the possibility of decreases in steel hardness due to tempering effects, enabling it to undergo rapid temperature increases and decreases.

\section{Introduction}

Laser surface processing technology has undergone more than 40 years of development and has been applied by numerous well-known international enterprises in the automotive, aerospace, military, shipbuilding, and material-related industries because of its abundant advantages for manufacturing the products of these industries. Unlike the conventional heat treatment method, laser surface heat treatment involves transmitting a laser beam through optics to irradiate a high-energy, high-intensity laser beam onto a metal surface to immediately facilitate austenite transformation. At room temperature and without any fixed thermal convection conditions, the austenite form of the metal surface undergoes martensitic transformation through self-quenching. ${ }^{(1)}$

In 1960, Maiman ${ }^{(2,3)}$ installed a ruby cylinder (diameter: $1 \mathrm{~cm}$; length: $2 \mathrm{~cm}$ ) on the axis of a helical xenon flashlamp, which was then inserted into a polished aluminum cylinder. When the ruby cylinder was illuminated by the flashlamp, the device emitted red light; hence, the first working laser was invented. According to DeMichelis, ${ }^{(4)}$ a German scientist used a laser beam to perform heat treatment on a metal, which was the first experiment in history

\footnotetext{
*Corresponding author: e-mail: jammy@kuas.edu.tw

** Corresponding author: e-mail: k0464@gcloud.csu.edu.tw

https://doi.org/10.18494/SAM.2019.2229
} 
to employ lasers as a heat treatment method. Scientists in the United States then started to study the absorption and hardening of a graphite-coated metal surface irradiated with a ruby laser beam. ${ }^{(5)}$ Researchers in the United States and Japan ${ }^{(6,7)}$ also began to examine the heat treatment ability of lasers on metal surfaces by observing their austenitization and to study the effects of laser heat treatment on alloys. In 1965, the Nd:YAG laser was the first industrial use of this technology to repair connectors inside assembled television tubes. ${ }^{(8)}$ Lasers were applied to industrial production in 1974, when the Saginaw Steering Gear Division, part of General Motors, began to use laser beams to harden steering gear housings. ${ }^{(9,10)}$ Loeffer ${ }^{(11)}$ proposed the first computer numerical control (CNC) laser soldering machine, which used a $\mathrm{CO}_{2}$ laser and keyhole welding technology. However, no mature dynamic equations were developed in related research until 1995, when Fuerschbach and MacCallum ${ }^{(12)}$ irradiated a $\mathrm{CO}_{2}$ laser beam onto 304 stainless steel at $6 \mathrm{MW} / \mathrm{cm}^{2}$ and derived the relationship among laser absorption rate, weld pool width, and weld pool depth using a weld pool geometry model.

Laser surface heat treatment has the following advantages: ${ }^{(1)}$ First, it causes the metal to self-quench; thus, the metal surface remains clean and does not require further cleaning after treatment. Second, changing the laser power and the position of the optics enables its application in heat treatment processes for different materials with different requirements. Third, laser sources installed on CNC machines can be used to perform heat treatment on workpieces with complex shapes. Fourth, workpieces that have received laser heat treatment undergo minimal deformation. Fifth, workpieces that have received laser heat treatment do not require grinding. Sixth, production can be automated, effectively reducing human resource costs.

Bojinović et al. ${ }^{(13)}$ proposed a 3D model of the laser hardening process using a highpower diode laser for $50 \mathrm{CrV} 4$ steel, based on the finite element method. Nguyen and Yang ${ }^{(14)}$ presented a sequential method to estimate surface absorptivity in the laser surface hardening process using a 1D transient conduction heat transfer model. Sarkar et al. ${ }^{(15)}$ proposed a modified 1D heat conduction model to analyze the effects of temperature and surface hardening on low-carbon thin steel (thickness: $1 \mathrm{~mm}$ ) using an Yb-fiber laser. Martínez et al. ${ }^{(16)}$ proposed a scanner-based laser hardening process for AI1045 steel and discussed the effects of scanning speed on the hardened layer thickness. Lakhkar et al. ${ }^{(17)}$ proposed a numerical model to predict the back tempering in multitrack laser hardening for AISO4140 steel. Recently, Cordovilla et al. ${ }^{(18)}$ have studied laser surface hardening analysis to propose the design of a suitable overlapping distance for Cr-Mo steel. Overall, the main difficulties are how to choose adequate laser technological parameters and a suitable laser scanning (tracking) method for surface hardening to obtain the optimum hardening quality with an excellent temperature field distribution.

In this study, the temperature distribution of SAE-AISI 1045, a medium carbon steel, was analyzed by adopting the finite element method as the numerical simulation tool and employing a neodymium-doped yttrium aluminum garnet (Nd:YAG) solid-state laser as the laser source. ${ }^{(19)}$ The material properties of SAE-AISI 1045 were obtained from Ding and Yung. ${ }^{(20)}$ In addition, on the basis of studies by Kusuhara et al., ${ }^{(21)}$ a thermo-elastic-plastic finite element model was constructed to examine and discuss the effects of laser feed rate, laser power, and laser spot 
size on the temperature distribution, the depth of the hardened layer (hardening depth), and the width of the laser-hardened area (hardening width). Moreover, the effects of the overlap and power level of a diode laser beam on the hardened layer depth of SAE-AISI 1045 were examined.

\section{Finite Element Modeling and Analysis}

By simulating and analyzing the application of a moving Gaussian laser beam as the source for the heat treatment of a tool steel surface, a set of research procedures to identify the adequate ranges of various process parameters was established in this study. We used a multitrack laser beam with a Gaussian profile to perform heat treatment under the effects of circular laser spots and examined the possible tempering effects of the laser beam during the heat treatment process. The details are described below.

\subsection{Setup of moving heat source}

The employed Nd:YAG laser was adjusted for heat source distribution in transverse electromagnetic mode $00\left(\mathrm{TEM}_{00}\right)$, as described in Ref. 22. This commonly used mode differs from that of a conventional welding heat source, which exhibits a bi-elliptic distribution. In the $\mathrm{TEM}_{00}$ mode, the power density is highest at the center of the beam and diminishes with increasing distance from the center, resulting in a Gaussian distribution of light intensity across the beam diameter. The power density of the laser $\left(E_{e}\right)$ in the $\mathrm{TEM}_{00}$ mode can be expressed as

$$
E_{e}\left(r_{e}\right)=P_{i} \cdot \Phi\left(r_{e}\right)
$$

where $r_{e}$ is the distance from the center of a laser beam, $P_{i}$ is the laser power size, and $F$ is the Gaussian distribution function. The center of the $2 \mathrm{D}$ Gaussian distribution was rotated $360^{\circ}$ to obtain a 3D Gaussian distribution, which is expressed as

$$
\Phi\left(r_{e}\right)=\frac{1}{2 \pi s^{2}} \exp \left(-\frac{r_{e}^{2}}{2 s^{2}}\right)
$$

where $s$ is the standard deviation of the Gaussian distribution. In accordance with the research in Refs. 22 and 24, the radius of the spot size, $R_{e}$, was used to calculate the area in which $95 \%$ of the laser beam power passes through a circle of its focused area, which can be written as

$$
\int_{0}^{2 \pi} \int_{0}^{R_{e}} \frac{1}{2 \pi s^{2}} e^{-\frac{r_{e}^{2}}{2 s^{2}}} r_{e} d r_{e} d \theta=0.95
$$

where $q$ is the angular variable. From Eq. (3), the following can be obtained: 


$$
s=\frac{R_{e}}{\sqrt{2 \ln (20)}} \approx \frac{R_{e}}{\sqrt{6}} .
$$

Substituting Eq. (4) to Eq. (2), Eq. (1) can be rewritten as

$$
E_{e}\left(r_{e}\right)=\frac{3 P_{i}}{\pi R_{e}^{2}} \exp \left(-\frac{3 r_{e}^{2}}{R_{e}^{2}}\right) .
$$

Because most materials are unable to fully absorb the energy of a laser beam, we considered the effects of the steel thermal absorptivity $\left(\eta_{e}\right)$. Referring to the data presented by DeKock, ${ }^{(25)}$ we set the thermal absorption rate $h_{e}$ at $40 \%$; thus, the final amount of energy absorbed by the steel $\left(P_{e}\right)$ can be expressed as

$$
P_{e}=\eta_{e} \cdot \frac{3 P_{i}}{\pi R_{e}^{2}} \exp \left(-\frac{3 r_{e}^{2}}{R_{e}{ }^{2}}\right) .
$$

The diameter of the laser spot set between 2 and $4 \mathrm{~mm}$ is chosen in this study.

\subsection{Construction of finite element model}

In this study, MSC.MARC, a commercial finite element analysis software program, was used as a numerical equation solving tool, and the pre- and post-Mentat processor provided by MSC.MARC was employed to construct a finite element model mesh and boundary conditions, and to obtain the temperature and stress data for the analysis node. AISI 1045 medium carbon steel was selected in bar-shaped pieces with dimensions of $100 \times 12 \times 6 \mathrm{~mm}^{3}(l \times w \times h)$. The use of a 3D finite element model mesh for multitrack laser heat treatment was proposed, as shown in Fig. 1. Note that the mesh in the $x$ - and $y$-directions is evenly distributed, but the mesh in the $z$-direction is smaller when close to the material surface. The moving heat source of the laser with heat distribution in the $\mathrm{TEM}_{00}$ Gaussian mode was simulated using MSC.MARC, as shown in Fig. 2.

\subsection{Multitrack laser heat treatment model}

Steel materials generally cool rapidly after laser treatment. To reduce the calculation time required for numerical simulation, the laser beam was fed through an S-shaped path (hereafter referred to as SSP), as illustrated in Fig. 3, which was employed in the heat treatment simulation model. Data were collected from nine nodes in the targeted treatment area (length: $l_{h}$; width: $3 \mathrm{~mm}$ ) on the surfaces of the steel materials, as shown in Fig. 4. In this article, the length of the proposed S-shaped laser track for the heat treatment was set at $3 \mathrm{~mm}$ to achieve a hardening width of $6 \mathrm{~mm}$ on the surface of the treatment area when the light spot diameter $\left(R_{i}\right)$ was $3 \mathrm{~mm}$. 


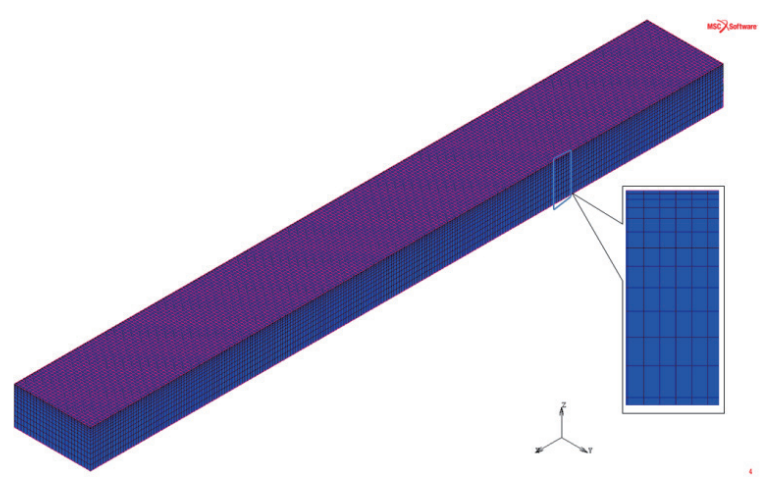

Fig. 1. (Color online) 3D finite element model mesh construction.

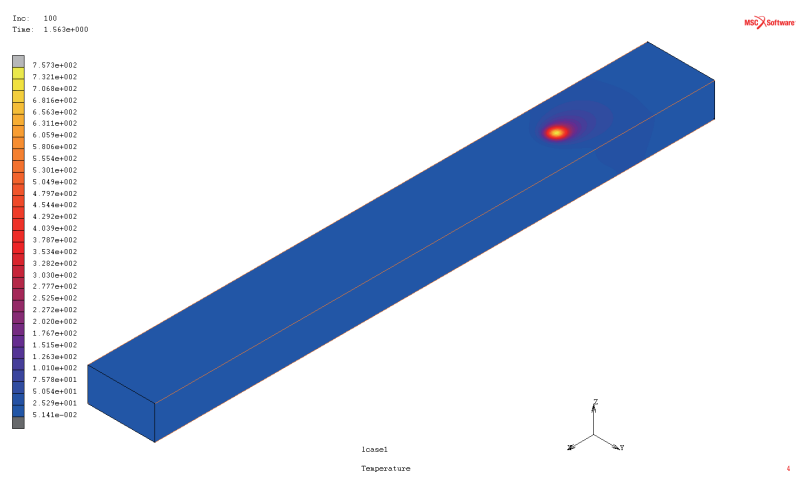

Fig. 2. (Color online) Moving heat source of laser.

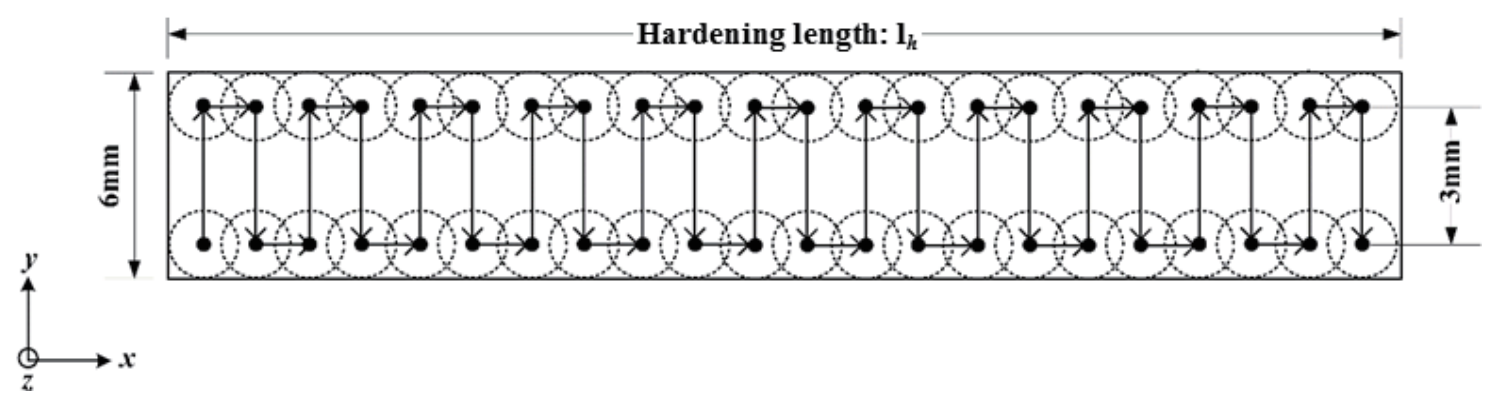

Fig. 3. SSP traced by multitrack laser heat treatment.

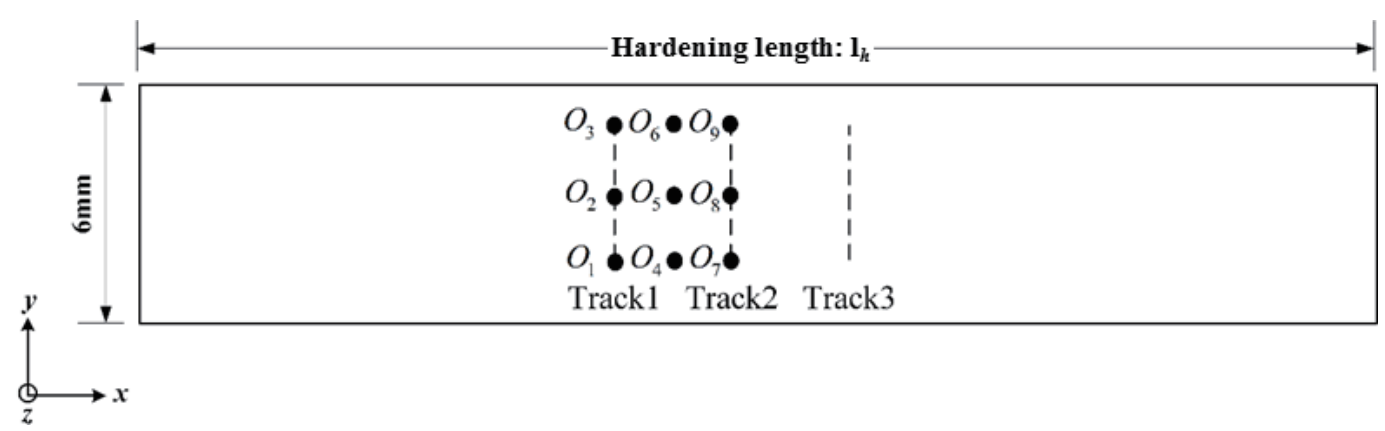

Fig. 4. Schematic of the nine nodes designating the data acquisition points during the multitrack laser heat treatment.

Figure 5 depicts the nine nodes (labeled $\mathrm{O}_{1}-\mathrm{O}_{9}$ ) selected from the area between the first and second laser tracks for temperature data acquisition and further analysis. In terms of laser power output, laser power and energy were continuously fed from the beginning to the end of the SSP. 


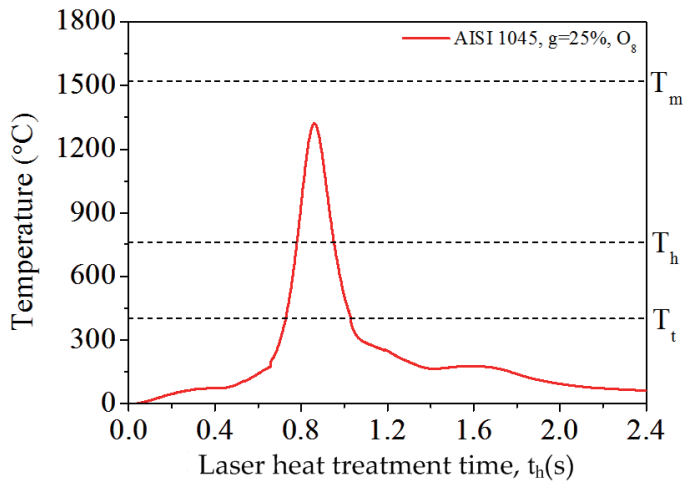

(a)

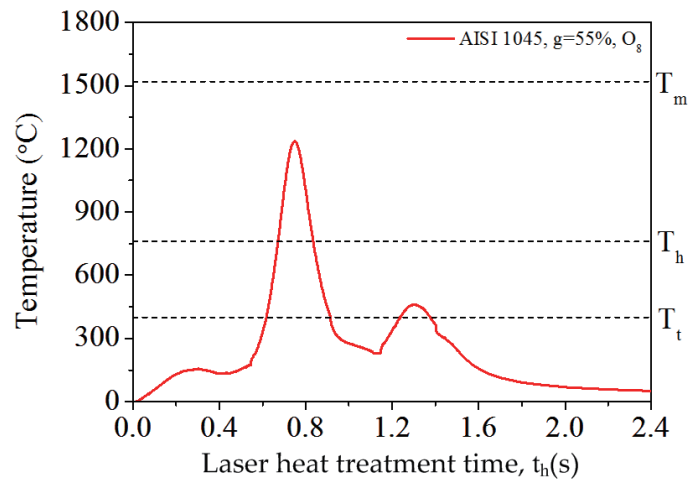

(b)

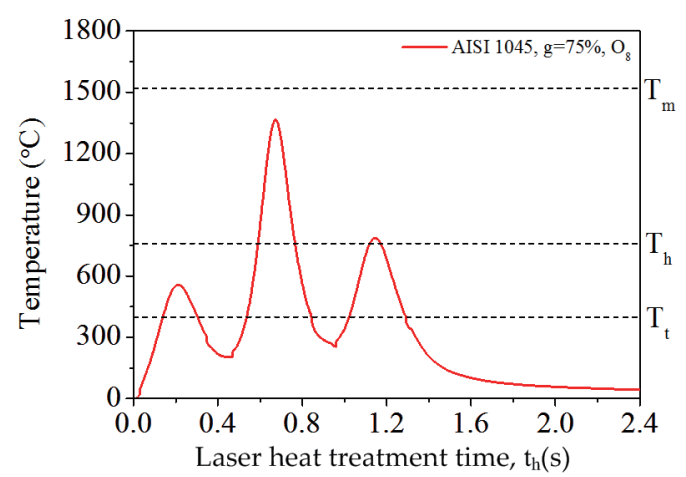

(c)

Fig. 5. (Color online) Temperature profiles of $\mathrm{O}_{8}$ on AISI 1045 at laser overlap rates of (a) 25, (b) 55, and (c) $75 \%$.

\section{Results and Discussion}

In this study, we examined the tempering effects of multitrack laser surface heat treatment by using the finite element method to simulate and analyze the effects of all process parameters on the heat treatment process. The appropriate ranges and optimal values of the process parameters were identified. The multitrack laser heat treatment process was analyzed to examine the tempering effects of these process parameters on multiple nodes along the surfaces of the materials. In the following subsection, the effects of laser overlap rate, laser power, laser feed rate, and laser spot size on the temperature distribution of AISI 1045 steel materials will be discussed. Because of the considerable amount of data collected from the nine nodes, not all of the nodes are presented in the figures; only nodes that reflected significant effects of the four parameters on temperature distribution, namely, $\mathrm{O}_{8}$ and $\mathrm{O}_{9}$, are discussed. $T_{p}$ denotes the highest peak temperature during the laser heat treatment.

\subsection{Effects of laser overlap rate on tempering effects}

This subsection focuses on analyzing the effects of laser overlap rate $(g)$ on the temperature profiles of nodes $\mathrm{O}_{8}$ and $\mathrm{O}_{9}$. The laser power $P_{i}$ was set at $350 \mathrm{~W}$, the laser feed rate $V_{i}$ at $8 \mathrm{~mm} / \mathrm{s}$, 
the laser spot size diameter $R_{i}$ at $3 \mathrm{~mm}$, and the laser feed path as the SSP. Figure 5 shows the temperature profiles of node $\mathrm{O}_{8}$ (see Fig. 4) on the steel material for laser overlap rates of $g=25$, 55 , and $75 \%$. It can be seen that these rates all generated temperatures above the quenching temperature $T_{h}$, which may have induced hardening. In addition, all of the $\mathrm{O}_{8}$ temperatures reached the tempering temperature, which might have caused tempering effects. Note that the tempering effects of $\mathrm{O}_{8}$ are relatively more prominent at $g=75 \%$. When the laser overlap rate is increased from 25 to $55 \%$, the first peak temperature decreases by $7 \%$, but the second peak temperature increases by $160 \%$. When the overlap rate is increased from 55 to $75 \%$, the first peak temperature increases by $252 \%$, the second by $10 \%$, and the third by $70 \%$.

Figure 6 illustrates the temperature profiles of node $\mathrm{O}_{9}$ on AISI 1045. Similarly to $\mathrm{O}_{8}$, the three laser overlap rates generated temperatures over the quenching temperature $T_{h}$ and induced hardening. At $g=55$ and $75 \%$, tempering effects might have occurred on node $\mathrm{O}_{9}$, and these effects were more prominent. When the rate was increased from 25 to $55 \%$, the first peak temperature remained unchanged, but the second peak temperature increased by $178 \%$. When the rate increased from 55 to $75 \%$, the first peak temperature increased by $14 \%$ and the second by $73 \%$. From the information in Figs. 5 and 6, we selected the temperature profile of the $55 \%$ laser overlap rate to discuss the effects of laser power, laser feed rate, and laser spot size on the tempering effects of $\mathrm{O}_{8}$ and $\mathrm{O}_{9}$.

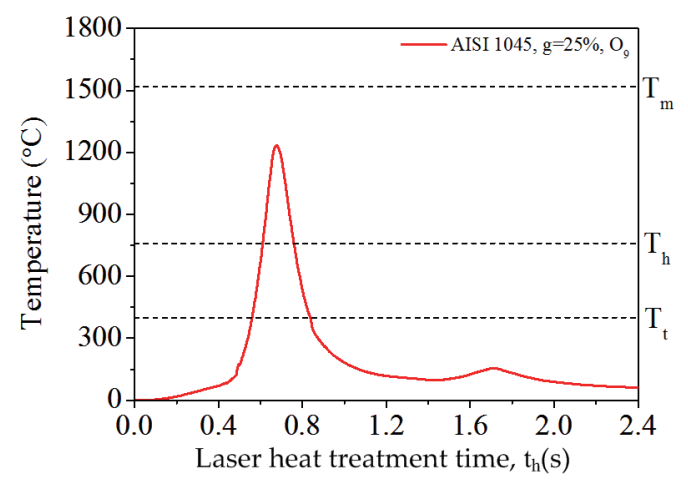

(a)

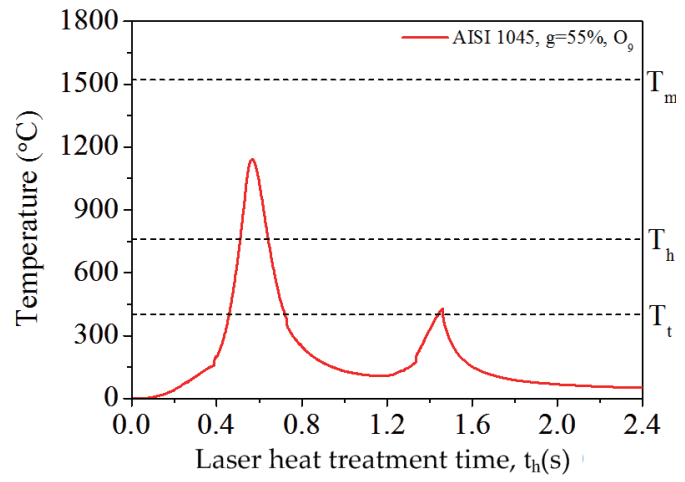

(b)

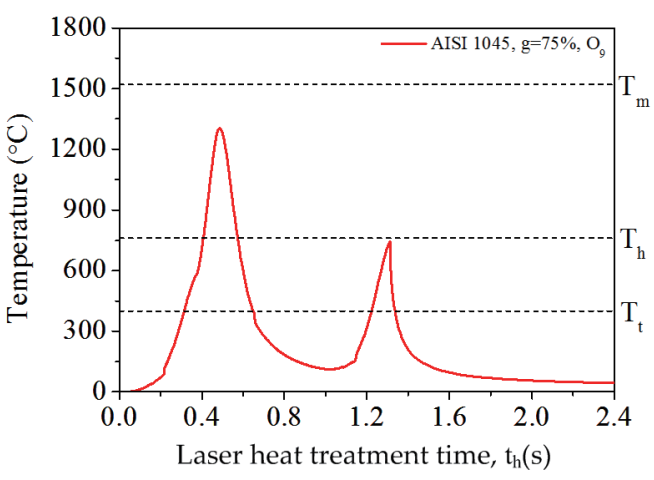

(c)

Fig. 6. (Color online) Temperature profiles of $\mathrm{O}_{9}$ on AISI 1045 at laser overlap rates of (a) 25, (b) 55, and (c) $75 \%$. 


\subsection{Effect of laser power on tempering effects}

In this subsection, the effects of laser power on the temperature profiles of $\mathrm{O}_{8}$ and $\mathrm{O}_{9}$ are examined. The laser feed rate $V_{i}$ was set at $8 \mathrm{~mm} / \mathrm{s}$, the laser spot size diameter $R_{i}$ at $3 \mathrm{~mm}$, the laser overlap rate $g$ at $55 \%$, and the laser feed path as the SSP. Figure 7 shows the temperature profiles of $\mathrm{O}_{8}$ for laser powers of $P_{i}=300,350$, and $400 \mathrm{~W}$. All these powers generated heat over the quenching temperature $T_{h}$ and may have induced hardening. When $P_{i}=300 \mathrm{~W}$, the third peak temperature reached the tempering temperature $T_{t}$. However, when $P_{i}=350$ and $400 \mathrm{~W}$, the third peak temperature was higher than the tempering temperature $T_{t}$ and might have caused tempering effects on the steel material. In particular, when $P_{i}=400 \mathrm{~W}$, the temperature at node $\mathrm{O}_{8}$ exceeded the melting temperature $\left(T_{m}\right)$ of AISI 1045, which could cause the steel to melt.

Figure 8 presents the temperature profiles of $\mathrm{O}_{9}$ for laser powers of $P_{i}=300,350$, and $400 \mathrm{~W}$. Similarly to $\mathrm{O}_{8}$, the generated temperatures for these laser powers were higher than the quenching temperature $T_{h}$ and hence might have caused hardening. However, the second peak temperature (tempering temperature) at node $\mathrm{O}_{9}$ increased by around $15-17 \%$ when its laser power was increased by $50 \mathrm{~W}$. We concluded that laser power control is not adaptive for SAEAISI 1045 and that $350 \mathrm{~W}$ is the suitable laser power.

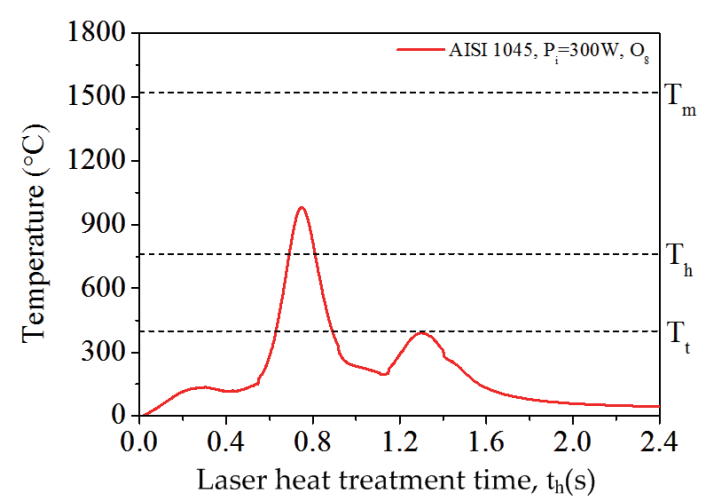

(a)

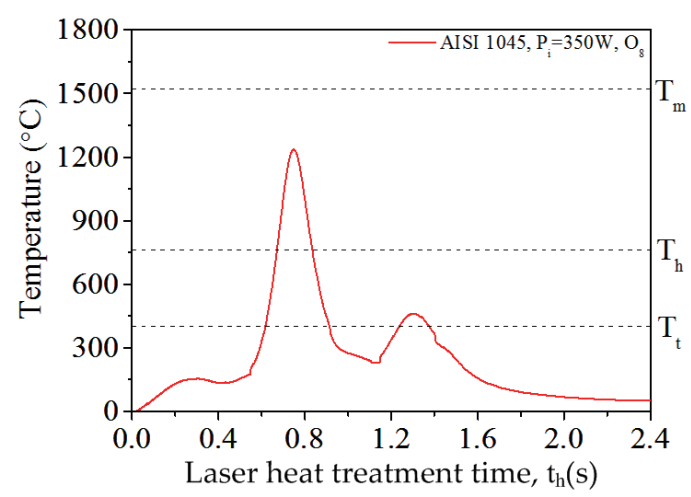

(b)

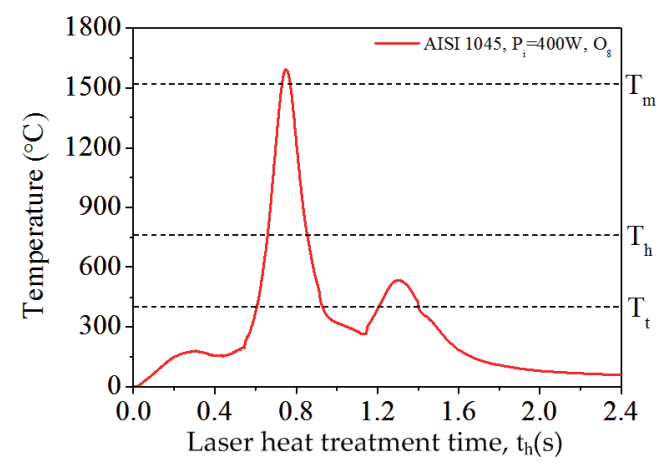

(c)

Fig. 7. (Color online) Temperature profiles of $\mathrm{O}_{8}$ at laser powers of (a) 300, (b) 350, and (c) $400 \mathrm{~W}$. 


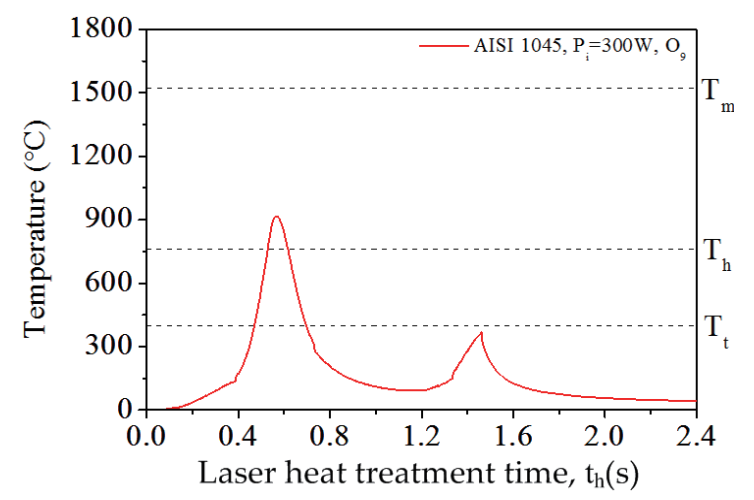

(a)

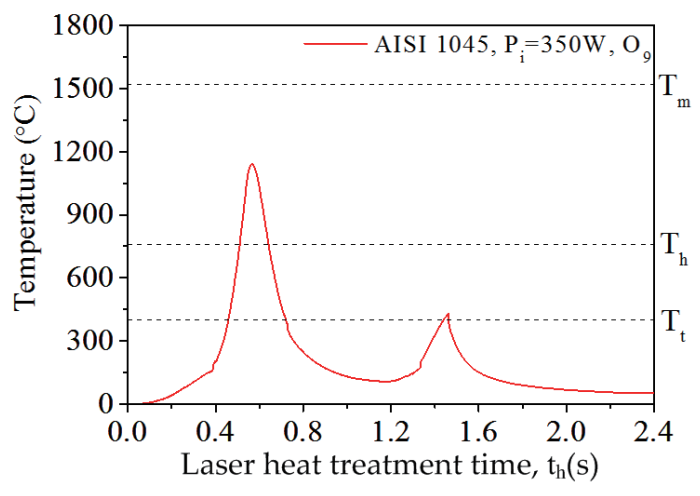

(b)

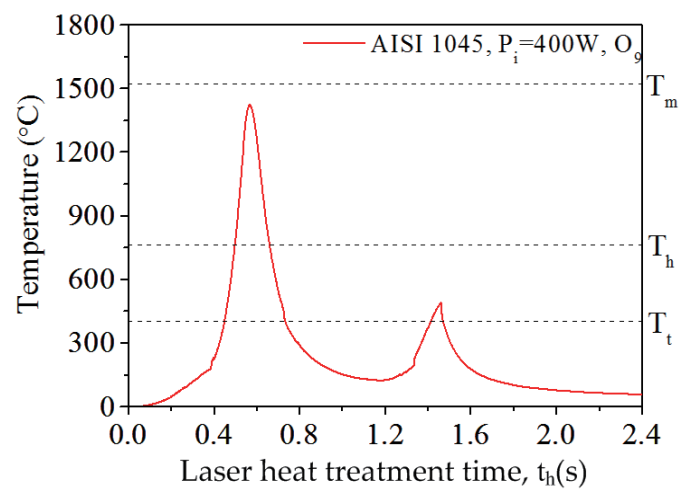

(c)

Fig. 8. (Color online) Temperature profiles of $\mathrm{O}_{9}$ at laser powers of (a) 300, (b) 350, and (c) $400 \mathrm{~W}$.

\subsection{Effect of laser feed rate on tempering effects}

In this subsection, the effects of laser feed rate on the temperature profiles of $\mathrm{O}_{8}$ and $\mathrm{O}_{9}$ are explored. The laser power $P_{i}$ was set at $350 \mathrm{~W}$, the laser spot size diameter $R_{i}$ at $3 \mathrm{~mm}$, the laser overlap rate $g$ at $55 \%$, and the laser feed path as the SSP. The temperature profiles of node $\mathrm{O}_{8}$ are given in Fig. 9 for three laser feed rates of $V_{i}=5,10$, and $15 \mathrm{~mm} / \mathrm{s}$. The temperatures on node $\mathrm{O}_{8}$ are higher than $T_{h}$ and could result in hardening. In these cases, the second peak temperature exceeded the tempering temperature $T_{t}$, causing tempering effects. Figure 10 presents the temperature profiles of node $\mathrm{O}_{9}$ for AISI 1045 at three different laser feed rates. These rates also contributed to heated temperatures higher than $T_{h}$ on $\mathrm{O}_{9}$ that might cause hardening. For laser feed rates of 5 and $10 \mathrm{~mm} / \mathrm{s}$, the second peak temperature reached or exceeded the tempering temperature $T_{t}$ and therefore would also cause tempering effects. A laser feed rate of $15 \mathrm{~mm} / \mathrm{s}$ would not induce tempering effects because the second peak temperature did not exceed $T_{t}$. Note that the second peak temperature (tempering temperature) of node $\mathrm{O}_{9}$ for AISI 1045 was reduced by approximately $13-18 \%$ when the laser feed rate was increased by $5 \mathrm{~mm} / \mathrm{s}$. From the simulation results shown in Figs. 9 and 10, we can conclude that tempering effects are better at node $\mathrm{O}_{9}$ than at node $\mathrm{O}_{8}$. 


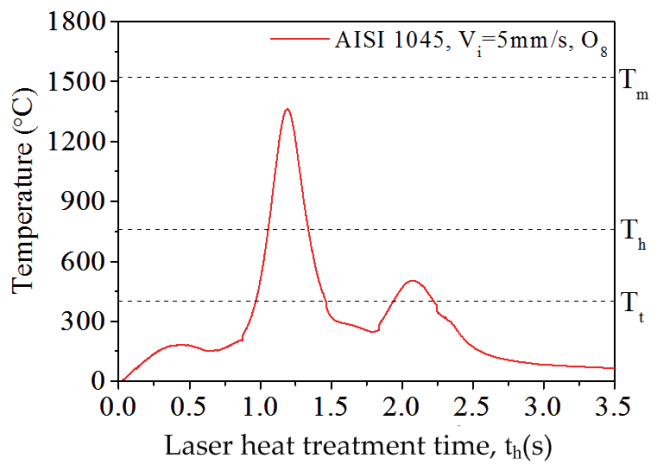

(a)

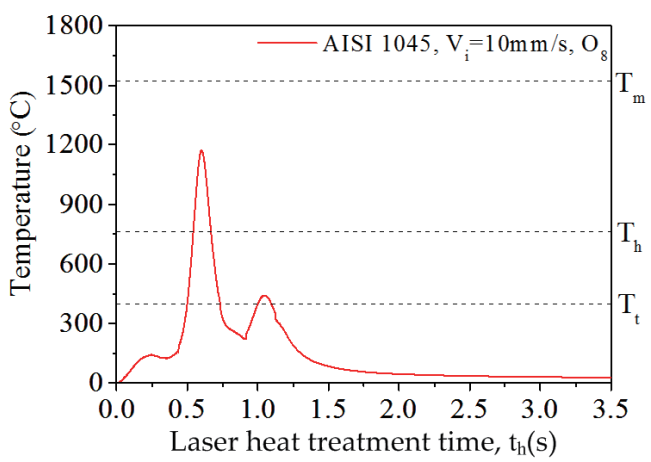

(b)

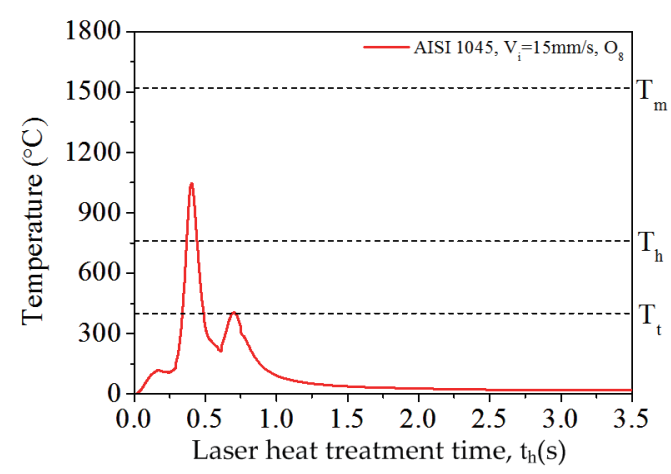

(c)

Fig. 9. (Color online) Temperature profiles of $\mathrm{O}_{8}$ at laser feed rates of (a) 5, (b) 10, and (c) $15 \mathrm{~mm} / \mathrm{s}$.

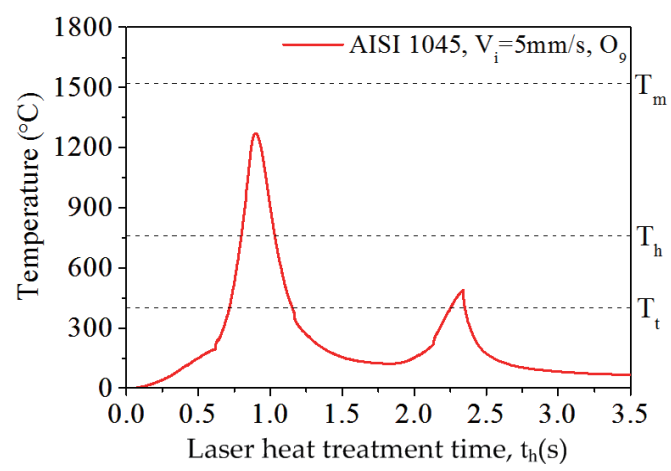

(a)

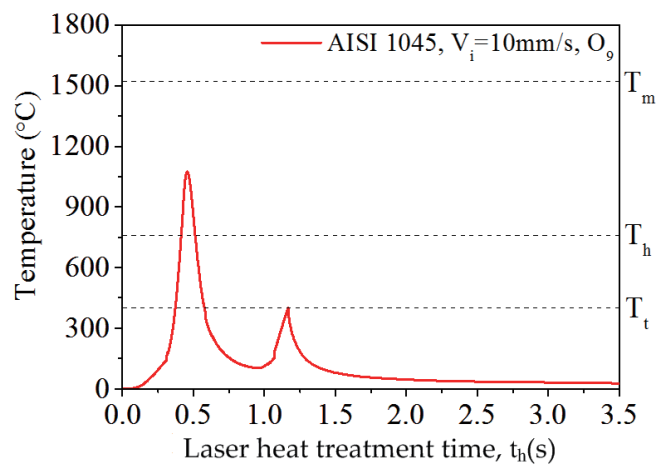

(b)

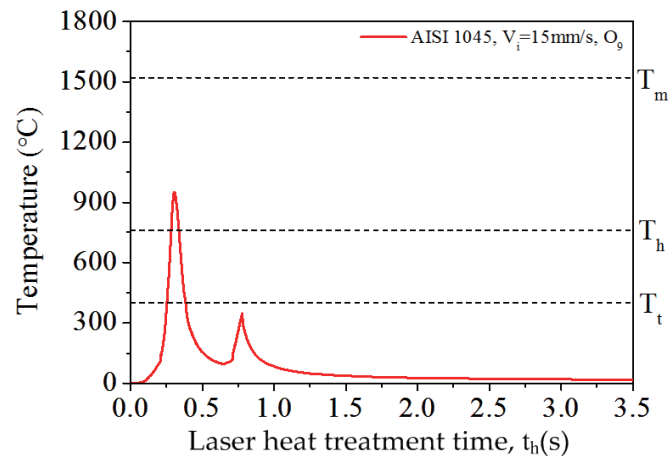

(c)

Fig. 10. (Color online) Temperature profiles of $\mathrm{O}_{9}$ at laser feed rates of (a) 5, (b) 10 , and (c) $15 \mathrm{~mm} / \mathrm{s}$. 


\subsection{Effect of laser spot size on tempering effects}

In this subsection, the effects of laser spot size on the temperature profiles of $O_{8}$ and $O_{9}$ are analyzed. The laser power $P_{i}$ was set at $350 \mathrm{~W}$, the laser feed rate $V_{i}$ at $8 \mathrm{~mm} / \mathrm{s}$, the laser overlap rate $g$ at $55 \%$, and the laser feed path as the SSP. Figures 11 and 12 respectively depict the temperature profiles of $O_{8}$ and $O_{9}$ for laser spot diameters of $R_{i}=2.8,3.0$, and $3.2 \mathrm{~mm}$. It can be observed from Figs. 11 and 12 that these spot diameters produced a temperature higher than $T_{h}$ at both $O_{8}$ and $O_{9}$, inducizng hardening. Note that AISI 1045 could also melt when $R_{i}=$ $2.8 \mathrm{~mm}$ because the heated temperature exceeded its melting temperature Tm. Also, note that the tempering effects of $O_{8}$ and $O_{9}$ would only occur when $R_{i}=3 \mathrm{~mm}$.

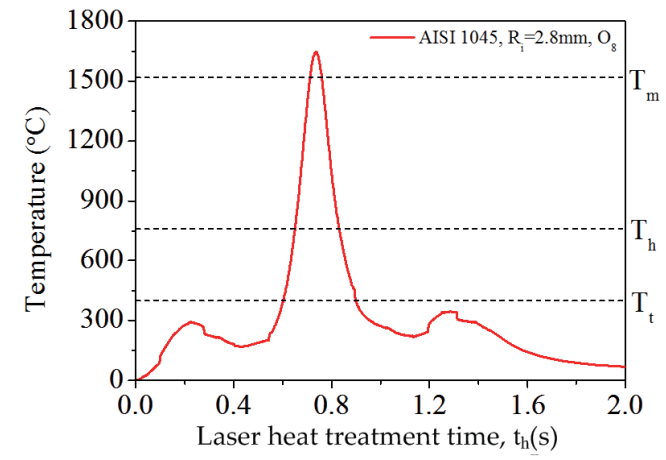

(a)

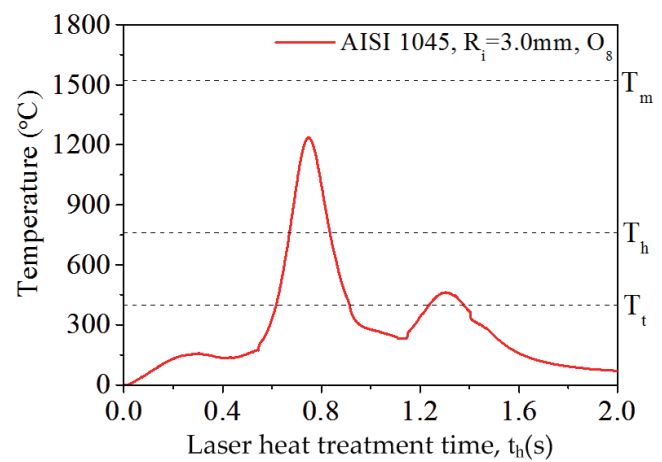

(b)

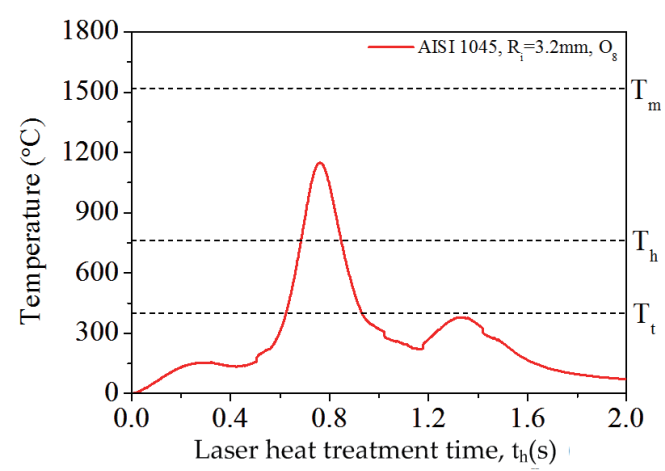

(c)

Fig. 11. (Color online) Temperature profiles of $O_{8}$ at spot sizes of $R_{i}=$ (a) 2.8, (b) 3, and (c) $3.2 \mathrm{~mm}$. 


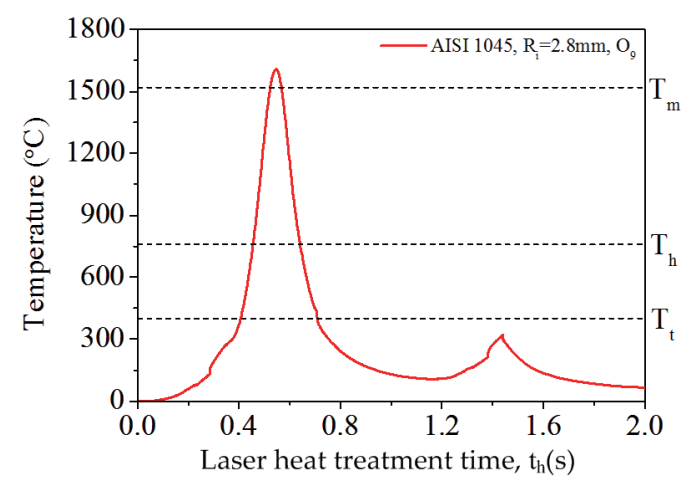

(a)

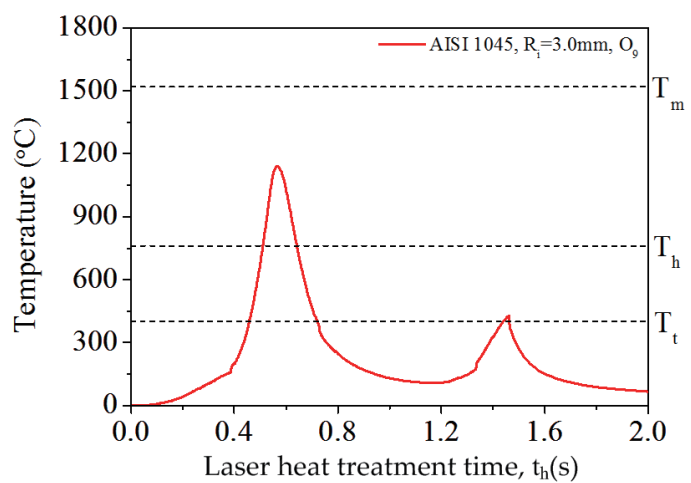

(b)

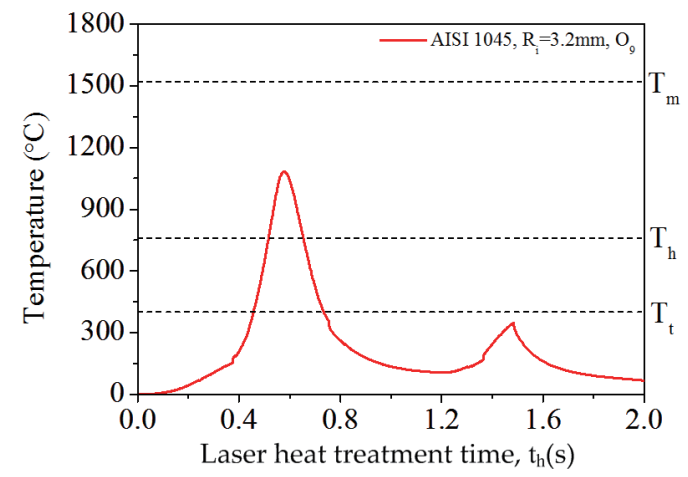

(c)

Fig. 12. (Color online) Temperature profiles of $O_{9}$ at spot sizes of $R i=$ (a) 2.8, (b) 3, and (c) $3.2 \mathrm{~mm}$.

\section{Conclusions}

In this study, a thermal-mechanical coupling model was utilized to simulate the peak temperature at the center of a laser spot as well as the hardening width and depth for various laser process parameters during the multitrack heat treatment of AISI 1045 medium carbon steel using a Nd:YAG laser. A finite element analysis model was proposed to effectively analyze the temperature field distribution on the surface of AISI 1045 for various process parameters during laser heat treatment. The obtained temperature field distributions on the material surface were used to observe and estimate the uniformity of the hardened surface layer and the relationship between tempering effects and process parameters. The appropriate ranges of the four process parameters - laser power, laser spot size, laser feed rate, and laser overlap rate - were identified for multitrack laser heat treatment. Numerical results reveal that the proposed finite element models are feasible for simulating the laser surface heat treatment process and tempering effects on AISI 1045 steel. Hence, the results may serve as a useful reference for researchers regarding the process parameters of laser heat treatment when conducting machining experiments.

\section{Acknowledgments}

The authors acknowledge partial financial support under grant no. MOST 106-2221-E-151017. 


\section{References}

1 J. H. Gur and J. Pan: Handbook of Thermal Process Modeling Steels (CRC Press, Boca Raton, 2009) p. 499.

2 T. Maiman: Phys. Rev. Lett. 4 (1960) 564. https://doi.org/10.1103/PhysRevLett.4.564

3 T. Maiman: Nature 187 (1960) 493. https://doi.org/10.1038/187493a0

4 C. DeMichelis: IEEE J. Quantum Electron. QE-6 (1970) 630. https://doi.org/10.1109/JQE.1970.1076329

5 D. Lichtman and J. F. Ready: Phys. Rev. Lett. 10 (1963) 342. https://doi.org/10.1103/PhysRevLett.10.342

6 G. R. Speich and A. Szirmae: Transform. Metall. Soc. AIME 245 (1969) 1063.

7 S. Namba, P. H. Kim, S. Nakayama, and I. Ida: Jpn. J. Appl. Phys. 4 (1965) 153. https://doi.org/10.1143/ JJAP.4.153

8 D. Belforte and M. Levitt: Industrial Laser Handbook (Springer-Verlag, New York, 1992) p. 13.

9 C. Wick: Manuf. Eng. 76 (1976) 35.

10 J. E. Miller and J. A. Wineman: Metal Prog. 111 (1977) 38.

11 J. R. Loeffer: Assembly Eng. 20 (1977) 32.

12 P. W. Fuerschbach and D. O. MacCallum: Proc. 14th Int. Congress on Applications of Lasers \& Electro-Optics (1995) 493-497.

13 M. Bojinović, N. Mole, and B. Štok: Surf. Coat. Technol. 273 (2015) 60. https://doi.org/10.1016/ j.surfcoat.2015.01.075

14 Q. Nguyen and C.-Y. Yang: Int. J. Heat Mass Transfer 95 (2016) 224. https://doi.org/10.1016/ j.ijheatmasstransfer.2015.11.087

15 S. Sarkar, M. Gopinath, S. S. Chakraborty, B. Syed, and A. K. Nath: Surf. Coat. Technol. 302 (2016) 344. https://doi.org/10.1016/j.surfcoat.2016.06.045

16 S. Martínez, A. Lamikiz, E. Ukar, A. Calleja, J. A. Arrizubieta, and L. N. Lopez de Lacalle: Opt. Lasers Eng. 90 (2017) 72. https://doi.org/10.1016/j.optlaseng.2016.10.005

17 R. S. Lakhkar, Y. C. Shin, and M. J. M. Krane: Mater. Sci. Eng., A 480 (2008) 209. https://doi.org/10.1016/ j.msea.2007.07.054

18 F. Cordovilla, Á. García-Beltrán, P. Sancho, J. Domínguez, L. Ruiz-de-Lara, and J. Ocaña: Mater. Design 102 (2016) 225. https://doi.org/10.1016/j.matdes.2016.04.038.

19 K. Wissenbach, A. Gillner, F. Dausinger, E. Beyer, and K. Wissenbach: Oberflächenbehandlung mit Laserstrahlung. Allgemaine Grundlagen (Springer-Verlag, Berlin, 1998) p. 19 (in German).

20 H. T. Ding and S. Yung: J. Manuf. Sci. Eng. 10 (2012) 051014. https://doi.org/10.1115/1.4007464

21 T. Kusuhara, J. Morimoto, N. Abe, and M. Tsukamoto: Proc. 4th Int. Conf. Modeling, Simulation and Applied Optimization (IEEE, 2011) 1-4.

22 C. Dawes: Laser Welding (Ablington Publishing and Woodhead Publishing in Association with the Welding Institute, Cambridge, 1992) p. 1.

23 T. Zacharia, S. A. David, J. M. Vitek, and T. Debroy: Weld. J. 68 (1989) 499.

24 T. Zacharia, S. A. David, J. M. Vitek, and T. Debroy: Weld. J. 68 (1989) 510.

25 J. DeKock: Laser Heat Treating Advances for the Gear Industry. http://www.gearsolutions.com/article/ detail/5632/laser-heat-treating-advances-for-the-gear-industry (accessed 2 April 2018). 